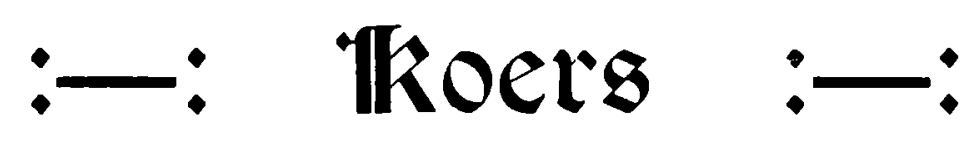

TWEEMAANDELIKSE TYDSKRIF

\begin{tabular}{lll}
\hline \hline JAARGANG XXIII. & APRIL 1956. & No. 5. \\
\hline \hline
\end{tabular}

\title{
TOELATING TOT DIE UNIVERSITEIT
}

Die toelatingsvereistes tot die universiteit vorm vir universiteit en vir student 'n uiters belangrike saak.

As die belangrikste vereiste vir toelating van studente tot ' $n$ universiteit is daar nog geen beter, doeltreffender en meer afdoende middel of kriterium gevind as die suksesvolle aflegging deur die student van 'n akademiese eksamen nie. Dit is waar in die geval van ons eie Suid-Afrikaanse universiteite, en ook net so waar vir enige universiteit waar in die wêreld dit mag bestaan.

Daarmee word nie gesê dat dit die enigste middel of kriterium is nie, maar alleen dat dit die belangrikste middel is. Tot beskikking van universiteite bestaan daar tans baie goeie en noodsaaklike hulpmiddele vir die vasstelling van die geskiktheid of ongeskiktheid van 'n aanstaande student vir hoër onderwys.

Vir toelating tot die Suid-Afrikaanse universiteite is die akademiese eksamen wat hierbo in gedagte was, die sogenaamde Matrikulasie-eksamen. Die term ,,matrikulasie" sien op die proses wat 'n student moet deurloop voor hy as 'n student aan 'n universiteit kan registreer. Matricula, die verkleinwoord van matrix, beteken 'n openbare rol of register, sodat matrikulering die proses van toelating tot inskrywing is. Die rol of register waarvan hier sprake is, is die rol of register van lidmaatskap van 'n liggaam of 
gemeenskap, in ons verband van 'n kollege of universiteit. 'n Gematrikuleerde student kan hom dus laat inskryf as lid op die rol of register van 'n universiteit of kollege. Die inskrywing van die eie naam op die rol of register stel die student dan in die voorreg van volle lidmaatskap en hy kan dan alle regte en voorregte van 'n volle lid geniet. Elke universiteit vereis dan vandag nog dat elke nuwe student hom moet laat registreer voor hy van enige reg of voorreg aan die universiteit gebruik kan maak.

Die Suid-Afrikaanse Matrikulasie-eksamen, die akademiese eksamen vir toelating tot die universiteit, vind sy begin in die stigting van die Universiteit van die Kaap die Goeie Hoop in 1873.

Aanvanklik is die eksamen deur die Universiteit self gelei. Die leerplan en die leergange sowel as die eksamens en eksaminatore is deur die Universiteit vasgestel. Die ou Matrikulasie-eksamen was 'n universiteitseksamen, en wel 'n universiteitstoelatingesksamen. In die Kalenders van die ou Kaapse Universiteit vind ons dan ook die volle besonderhede van die eksamen.

Die belangrikste besonderhede van die ou eksamen is: 'n leeftydsgrens van minstens 16 jaar, 'n sertifikaat van goeie gedrag, 'n leerplan en die betrokke leergange.

'n Omvattende en byna eenvormige leerplan is voorgeskryf. In die Kalender (Jaarboek) vir die jaar 1875 word die „By-laws and Regulations” so gestel wat betref die leerplan:

Kandidate sal geëksamineer word in:

I. Tale, Letterkunde en Geskiedenis:

(1) Engels, (2) Engelse Geskiedenis, (3) Grieks en Latyn, (4) 'n Moderne taal: Hollands of Frans of Duits.

II. Wiskunde:

(1) Rekenkunde, (2) Elementêre Algebra, (3) Vlak Meetkunde.

III. 'n Natuurwetenskap: Fisiese Aardrykskunde of Geologie of Chemie.

Geen kandidaat sal deur die eksaminatore goedgekeur word nie, tensy hy in die volgende vakke voldoende kennis besit:

1. Engelse Taal, Engelse Geskiedenis en Moderne Aardrykskunde,

2. Latyn,

3. Rekenkunde, 4. Algebra en 5. Meetkunde.

Die verpligte vakke is dus: Engels, Geskiedenis, Aardrykskunde, Latyn en Wiskunde.

In die laaste Kalender, die vir 1916-17, vind ons die toedrag van sake 
vir 1916, waarna as gevolg van Wet No. 12 van 1916 nuwe reëlings ingetree het.

Die vakke van die eksamen was toe:

GROEP I. (1) Engels A of Hollands A, (2) Latyn, (3) Wiskunde.

GROEP II: 'n Natuurwetenskap.

GROEP III: Grieks of Geskiedenis en een uit 'n aantal moderne tale of Hebreeus.

Die eksamen het toe vereis die welslae in elk van ses akademiese vakke met 'n minimum gemiddelde.

Met die stigting van twee selfstandige universiteite (Kaapstad en Stellenbosch) en van die federale Universiteit van Suid-Afrika by Wet No. 12 van 1916, het dit nodig gew.ord om 'n gesamentlike raad vir die Matrikulasieeksamen in die lewe te roep. So het die Gemeenskaplike Matrikulasieraad (G.M.R.) in beheer gekom van die toelating tot die universiteite.

Volgens die nuwe Regulasies van 1916 moet elke leerling eksamen affê in ses akademiese vakke: Groep I: Engels A of Hollands A, Latyn, Wiskunde, Groep II: een Natuurwetenskap en Groep III: Grieks of Geskiedenis en een moderne taal of Hebreeus. Met ander woorde, die G.M.R. het voortgegaan-altans aanvanklik-met die leerplan van die ou Kaapse Universiteit.

Ten tye van die afstigting van die laaste twee kolleges van die federale Universiteit in 1950 en die aparte voortbestaan van die Universiteit van SuidAfrika, het die Regulasies vir die Matrikulasie-eksamen die volgende vereistes reeds neergelê:

(a) Verpligtend: Engels A of Afrikaans A, 'n tweede taal, Wiskunde of 'n natuurwetenskap en 'n derde taal.

(b) Verder 'n keuse van minstens twee vakke uit 'n baie uitgebreide lys van vakke, insluitende vakke soos Boekhou, Huishoudkunde, Musiek.

Nog steeds geld die algemene vereiste dat 'n kandidaat vir toelating tot 'n universitet in 'n akademiese eksamen met 'n minimum aantal vakke 'n vasgestelde minimum gemiddelde moet behaal. As hy aan die eksamenvereistes voldoen, $k$ an hy hom by ' $n$ universiteit laat registreer.

Die vraag is nou of dit voldoende waarborg is vir sukses op die universiteit.

Hierdie vraagstuk neem tans groot afmetings aan. Baie meer studente slaag nie alleen in die Matrikulasie-eksamen nie maar meld hulle ook aan vir inskrywing op die rol van die universiteite.

Die pynlike gevolg van die toename in getalle studente is die toename 
in die getalle wat jaarliks nie die paal haal nie. 'n Verskynsel wat in die afgelope paar jaar die aandag van almal sterk trek, is die sg. groot persentasie onsuksesvolle kandidate, veral in die eerste jaar van hul universitêre loopbaan.

Dit word beweer dat die persentasie mislukkings te hoog is, en dit word geëis dat die oorsake van die mislukkings vasgestel en uit die weg geruim moet word.

Is dit inderdaad so dat te veel eerstejaarstudente druip? Indien dit so is, wat is die oorsake en hoe kan die druipingsyfer laer gebring word?

\section{2.}

Die vraagstuk van die aansienlike aantal mislukkings in die eerste jaar aan die universiteit moet ons nie los sien van die groot taak van die universiteit nie. Daarom moet ons ons ondersoek hier begin deur baie duidelik en skerp neer te lê wat die aard van die studiewerk op 'n universiteit is. Die studente in die studiejare skiet te kort, as hulle te kort skiet, in die verrigting van hul akademiese taak. En dit is van tweërlei aard: die beoefening van die vakwetenskappe en die aflegging van 'n akademiese eksamen aan die end van die jaar.

Die beoefening van die vakwetenskappe kan weer van twee kante benader word: die onderrigwerk deur die dosent en die studeerwerk deur die student.

Onderrig en studeer geskied op die universiteit op die hoë vlak van intellektuele arbeid. 'n Universiteit tog is 'n inrigting vir hoër onderwys. Van dosent en student verlang ons dus die hoë verstandsvermoë om die inhoud en metode van die vak te vat. Sonder die nodige verstandelike bevattingsvermoë kan die werk op 'n universiteit nie na behore verrig word nie. Om dit nou maar prontuit te druk: universiteitswerk is werk vir slim of skrander mense. Verstandelik dom mense kan dit eenvoudig nie bevredigend verrig nie.

Dit moet ons dan as die absolute sina quo non vir toelating tot die universiteit stel en as die voorvereiste vir suksesvolle studie. Ons kan dit veilig so stel: 'n sekere peil van verstandelike bekwaamheid of begaafdheid. 'n Sekere peil van verstandsaanleg is dus voorwaarde. As ons dit kan verseker by toelating, sal ons baie van die mislukkings kan voorkom.

Die vraag is nou net: waar val die grenslyn van verstandelike aanleg vir suksesvolle arbeid op die universiteit?

Verstandelike aanleg kan vandag met 'n baie groot mate van sekerheid bepaal word reeds vroeg in die lewe van die mens. Voor 'n student hom wil inskryf, kan ons reeds weet min of meer wat sy verstandelike begaafdheid 
is. Dit geskied deur die wetenskaplike metode van verstandsmeting. Met die metode kan ons baie noukeurig die intelligensiekwosiënt (I.K.) van 'n mens vasstel. Die bevindinge van die verstandsmeting word gewoonlik so ingedeel: die normale mens het 'n I.K. tussen 90 en 110, die swak begaafde mens onder 90 en die goed begaafde mens bo 110: hoe laer hoe swakker en hoe hoër hoe beter.

Met iemand met 'n I.K. bo 110 moet dit beter op die universiteit gaan as met iemand met 'n I.K. daaronder, mits ander faktore buite rekening gelaat word, want daar is ander faktore in die spel. Maar een feit bly as 'n paal bo water staan: Dom mense vorder nie op die universiteit nie en skrander mense kan daar vorder.

Skrander mense vaar gewoonlik goed op die universiteit, maar dat daar onder hulle ook minder suksesvolle studente is, weet iedereen. Dit kom egter veral in die eerste jaar voor, terwyl hulle selde in die tweede en derde jaar moeilikheid ondervind.

Die grootste meerderheid onder die druipelinge-in al drie die voorgraadse jare-kom uit die minder skrandere groepe, d.w.s. die dom en die normaal begaafdes: hoe laer die I.K., hoe groter die persentasie druipelinge. Aan die ander kant is dit geen ongewone gebeurtenis nie dat sekere studente van die minder skrandere groepe redelik goed op die universiteit vorder ten spyte van hulle betreklike lae I.K. Die beslissende faktor vir hul sukses is opregte en gewetensgetroue toewyding.

So het ons die twee grootste faktore vir sukses op die universiteit gestel: skranderheid en toewyding. As die twee faktore saamgaan, dan kry ons die briljante student. Die briljante student is iemand met 'n hoë I.K. en 'n hoë toewyding. In die taal van die Empiriese Opvoedkunde is hy iemand met 'n korrekte prestasiekwosiënt: hy werk soos hy kan en moet werk! Die ervaring leer ons egter dat daar sommige skrander studente met 'n lae prestasiekwosiënt en baie minder skrandere met 'n hoë prestasiekwosiënt is, en die laastes is gewoonlik studente wat hulle oorwerk.

Ons taak om vas te stel waarom daar te veel druipelinge is, is dus deels vereenvoudig en deels bemoeilik. Skrander studente behoort goed te vorder en minder skranderes kan alleen deur harde werk bevredigend vorder. As 'n skrander student sleg vorder, dan ontbreek by hom toewyding en inspanning. As 'n minder skrander student sleg vorder, dan kan daar ook bykom gebrek aan toewyding en inspanning.

Die saak werk dus eintlik heen op 'n vasstelling van die gronde vir gebrek aan toewyding en inspanning. 
En hier word die moontlike faktore byna onoorsienbaar in aantal en ingewikkeldheid. Al wat in 'n kort artikel gedoen kan word, is om hulle te groepeer. Daar is in die eerste plek suiwer persoonlike faktore in die spel. By die skranderes is dit veral oormoedigheid - dit sal wel goed gaan deur eie skranderheid - en gevolglik te min inspanning. By die minder intelligente is dit veral kleinmoedigheid - dit sal tog maar niks baat nie - en gevolglik weer eens te min inspanning. By almal kan dit wees gebrek aan belangstelling in 'n bepaalde vak of vakke of selfs in die hele akademiese rigting - ook skrander studente besit soms min belangstelling vir sekere vakke. By almal kom ook nog in rekening gebrek a" selfbeheersing en selfdissipline - hierdie gebrek is nie die las van dic minder begaafdes alleen nie. Daar is in die tweede plek fisiologiese faktore, waaraan alle studente onderworpe is of kan wees. Ek noem maar net swak gesondheid oor die algemeen, onderworpenheid aan veelvuldige klein aandoenings soos verkoue, allergiese verskynsels soos hooikoorsagtigheid, gesig- en gehoorgebreke, gevoeligheid vir vermoeidheid. Daar is in die derde plek allerlei sosiale invloede wat stremmend inwerk op behoorlike vordering. Hieronder val sowel die swakke as die skrandere. Onder die invloede moet ons reken veral slegte hüuslike omstandighede, siekte en dood van familielede, te veel sport, vergaderings en gesellighede en veral vermaaklikhede soos bioskoopbesoek, en selfs versteurings in die liefdesverhoudings. In die vierde plek moet genoem word sosio-ekonomiese faktore soos slegte inwoning tuis of by private mense of koshuise, eie finansiële moeilikhede, vermoeienis deur daelikse reise. Ten slotte moet ons ook wys op suiwer pedagogiese moeilikhede. Die vernaamste moeilikheid hier is die keuse van die studierigting. Dit kom voor by die minder begaafde sowel as by die hoog begaafde. Naas gebrek aan verstandelike eenleg en gebrek aan toewyding in die verkeerde keuse van studievakke op die universiteit seker die grootste oorsaak van mislukkinge. Daarom gee elke skool en universiteit vandag so baie aandag aan voorligting van jong studente. Daar is 'n aansienlike persentasie studente wat belangstel in 'n sekere studierigting sonder die nodige aanleg daarvoor te hê. 'n Tweede pedagogiese moeilikheid vloei voort uit die essensiële metodeverskille tussen die universiteit en die skool. Op skool het die kind gewoond geraak aan die byna volledige leiding deur die onderwyser, terwyl die universiteit vereis selfstudie en wetenskaplike gebruik van 'n biblioteek. Daarom sukkel eerstejaarstudente so baie: hulle is nog te afhanklik van die dosent, maar baie dosente hou ook nie rekening met die afhanklike houding van die beginner nie. 
Die Inetode van onderrig en studie verskuif die swaar taak van onderwyser op student. 'n Verdere moeilikheid lê hierin: dosente op die universiteit is spesialiste. Die gevolg is dat elke dosent die hoogste eise aan elke student stel: studie-eise, maar ook intelligensie-eise. Op die universiteit staan die wetenskap eerste. Hieraan is die jong student nie gewoond nie-op skool was die kind die eerste. 'n Verdere pedagogiese moeilikheid lê in die eksamenstelsel van die universiteit. Die eksamens van die skool is ingerig op die behoeftes en parate kennis van die kind. Die eksamens van die universiteit is ingerig op die vereistes van die eksaminator as vakkundige en op die wetenskaplike kennis en veral insig van die student. En dit is 'n geweldige oorgang! Ten slotte is daar nog die allerbelangrikste nuwe atmosfeer waarin die jong student land! Dit is geen skool weer, 'n plek van allerlei reels en regulasies nie. Dit is 'n universiteit, 'n plek met veel meer vryheid en selfverantwoordelikheid.

3.

Ons moet hierdie bespreking afsluit deur kortliks die moontlike middele om die moeilikhede uit die weg te ruim onder die oë te sien.

Die aanname van studente vir gevorderde studie is die verantwoordelikheid van die universiteit. Die universiteit moet alles in sy vermoe̊ doen om alle moeilikhede te ondervang, te voorkom, te vermy, uit die weg te ruim.

Die eerste verantwoordelikheid van die universiteit is die keuring van sy studente by toelating. Dit is 'n essensiële stuk werk maar gelyktydig 'n netelige taak. Sonder twyfel moet 'n ordentlike persentasie van die mislukkinge op die universiteit toegeskryf word aan die onomstootlike feit dat sommige studente weens onvoldoende verstandelike aanleg nooit aan die hoë eise kan voldoen nie. Die vraag is of ' $n$ universiteit die minder begaafde kind moet aanvaar as student. Soos sake vandag egter staan, is die algemene beleid eenvoudig maar om alle koring te maal wat aangebied word! Universiteite wil mos graag groot, soms die grootste wees! In 'n ernstiger gees, die bedryfslewe van 'n universiteit is afhanklik van sy getal studente-en dit is maar net menslik om die getal so hoog moontlik op te skuif.

Maar die universiteite laat nie alleen verkeerde studente toe nie, hulle gee ook nie altyd voldoende aandag aan die bestaansmoontlikheid van die wat toegelaat is nie. Die universiteite behoort hul studente uit te soek en die wat dan gekeur is, die regte leiding te gee, want studente bly maar jongmense!

Die eerste kriterium vir toelating tot die universiteit behoort te wees 
die suksesvolle aflegging van die akademiese toelatingseksamen, t.w. die Matrikulasie-eksamen-hoe beter daarin geslaag, hoe beter die kans vir toelating. Voorkeur moet gegee word aan die wat in die eersteklas-en liefs met onderskeiding-geslaag het.

Maar by die eerste kriterium kom dierek 'n tweede. Matrikulering, dus rypwording vir toelating tot die rol van die universiteit, geskied deur onderrig aan 'n middelbare skool. Die skolastiese geskiedenis van die leerling lê opgeskryf in die geskiedrolle van die skool, tans gewoonlik in die vorm van 'n Kumulatiewe Skoolrekord. Vir die universiteit is dit van die uiterste belang, want dit sal die uitslag van die Matrikulasie-eksamen bevestig, aanvul, moontlik weerspreek. Geen universiteit kan sonder 'n verslag van die skoolhoof met gerustheid 'n student aanvaar nie. In sekere oorsese lande speel dit 'n beslissende rol: sekere goedgekeurde skole se leerlinge word sonder meer as geskikte studente aanvaar. Dit is die waardevolle stelsel van akkreditering van skole: Sulke skole is besonder gestel op die eer, reg en voorreg dat die universiteit hul studente voetstoots inskryf. Dit is 'n beleid wat in Suid-Afrika gerus oorweeg kan word deur die G.M.R.

'n Derde kriterium vir beoordeling geld alleen in die geval van goeie studente. Dit is die verwerwing deur' $n$ aanstaande student van 'n beurs op grond van 'n sg. beurseksamen, wat ingestel is deur een of ander liggaam of organisasie wat studiebeurse beskikbaar stel. Sulke studicbeurse word egter soms ook, om ander oorwegings as net intellektuele bevoegdheid toegeken.

'n Vierde, steeds belangriker wordende, kriterium vir toelating is sekere moderne opvoedkundig-psigologiese toetse. Onder die toetse moet ons in die eerste plek stel die intelligensietoetse, waarmec die I.K. van 'n mens vasgestel kan word. Eintlik is die toetse onmisbaar vir toelating tot die hoër onderwys, omdat hoër onderwys 'n hoë I.K. vereis. Belangrik ook is die sg. wilstemperamentstoetse, spesiale aanlegtoetse en vakwetenskaplike kennistoetse. Twee besonder waardevolle middele om die bekwaamheid in die algemeen vas te stel, is opsteltoetse en woordeskattoetse, waarvan die laaste ongetwyfeld besonder betekenisvol is.

Ten slotte kan 'n rustige, deeglike persoonlike onderhoud veel bydra tot die wetenskaplike beoordeling van 'n jong student.

Al hierdie en ander middele is nodig om die student op die regte pad te bring. Maar selfs die bestes onder die gekeurdes kan in die loop van hul studiejare, veral die eerste jaar, nie aan die verwagtings voldoen 
nie. Daarom moet daar spesiale aandag gegee word aan twee uiters belangrike sake.

Die eerste gaan oor die student se vakkeuse. 'n Student is jonk en onervare en kies soms nie alleen verkeerde vakverbindings nie maar 'n heeltemal verkeerde graadrigting. Hy kies byvoorbeeld 'n B.Sc.-kursus terwyl hy daarvoor min aanleg het en beter sou vaar met 'n B.A.-kursus. Die universiteit moet elke student adviseer in dié verband. In die tweede plek moet elke universiteit 'n nasorgdiens toepas. As die jong student gekeur is en goed gekies het, moet daar gedurig toesig uitgeoefen word. Aandag moet gegee word aan sy klasbewoning en aan sy werkverrigting. Gedurende die eerste jaar veral moet daar in mindere of meerdere mate nog 'n pedagogiese toesig uitgcoefen word. Studente moet leer om self te werk!

J. CHR. COETZEE. 